\title{
Tuberculosis — United States, 2019
}

\author{
Noah G. Schwartz, MD ${ }^{1,2}$; Sandy F. Price ${ }^{1}$; Robert H. Pratt ${ }^{1}$; Adam J. Langer, DVM ${ }^{1}$
}

Since 1989, the United States has pursued a goal of eliminating tuberculosis (TB) through a strategy of rapidly identifying and treating cases and evaluating exposed contacts to limit secondary cases resulting from recent $\mathrm{TB}$ transmission (I). This strategy has been highly effective in reducing U.S. TB incidence (2), but the pace of decline has significantly slowed in recent years (2.2\% average annual decline during 2012-2017 compared with 6.7\% during 2007-2012) (3). For this report, provisional 2019 data reported to CDC's National Tuberculosis Surveillance System were analyzed to determine TB incidence overall and for selected subpopulations and these results were compared with those from previous years. During 2019, a total of 8,920 new cases were provisionally reported in the United States, representing a $1.1 \%$ decrease from $2018 .{ }^{*} \mathrm{~TB}$ incidence decreased to 2.7 cases per 100,000 persons, a $1.6 \%$ decrease from 2018. Non-U.S.-born persons had a TB rate 15.5 times greater than the rate among U.S.-born persons. The U.S. TB case count and rate are the lowest ever reported, but the pace of decline remains slow. In recent years, approximately $80 \%$ of U.S. TB cases have been attributed to reactivation of latent TB infection (LTBI) acquired years in the past, often outside the United States (2). An expanded TB elimination strategy for this new decade should leverage existing health care resources, including primary care providers, to identify and treat persons with LTBI, without diverting public health resources from the continued need to limit TB transmission within the United States. Partnerships with health care providers, including private providers, are essential for this strategy's success.

Health departments in the 50 U.S. states and the District of Columbia (DC) report all TB cases that meet the Council of State and Territorial Epidemiologists' surveillance case definition $^{\dagger}$ to CDC. Reports include patient demographics, clinical features, and medical and social risk factors. Self-reported race/ ethnicity data are collected and reported following federal standards; Hispanics/Latinos can be of any race, and all other reported race categories are non-Hispanic/Latino. The U.S. Census Bureau defines a U.S.-born person as one born in the United States or a U.S. territory or born abroad to a U.S. citizen parent. Rates (cases per 100,000 persons) were calculated for the United States and administrative divisions (i.e., the 50 states, DC, and census divisions) using midyear U.S.

\footnotetext{
*This report is limited to National Tuberculosis Surveillance System case reports verified as of March 3, 2020. Updated data will be available in CDC's annual TB surveillance report later this year.

${ }^{\dagger}$ https://www.cdc.gov/tb/programs/rvct/instructionmanual.pdf.
}

Census Bureau population estimates. ${ }^{\S}$ Rates by national origin and race/ethnicity were calculated using midyear Current Population Survey estimates. Average annual percentage changes (APC) in incidence were calculated for 2007-2012 and 2012-2019; these years were selected based on previous research demonstrating a statistically significant change in incidence trends during 2007 and 2012 (3). Data regarding drug-resistant TB cases are reported for 2018, the most recent year for which complete drug-resistance data are available.

U.S. TB incidence decreased an average of $2.1 \%$ per year during 2012-2019, a slower rate of decline than the average $6.4 \%$ per year during 2007-2012. The overall U.S. TB rate for 2019 was 2.7 cases per 100,000 persons, while state-specific 2019 TB rates ranged from 0.2 (Wyoming) to 8.1 (Alaska) (Table 1). Nine states (Alaska, California, Georgia, Hawaii, Maryland, New Jersey, New York, Texas, and Washington) and $\mathrm{DC}$ reported TB rates higher than the national rate. Four states (California, Florida, New York, and Texas) continued to account for approximately half of all reported TB cases.

Among 8,920 TB cases reported during 2019, a total of 6,322 (70.9\%) occurred among non-U.S.-born persons (Table 2). From 2018 to 2019, the rate among U.S.-born persons declined $4.2 \%$ (to 0.9 cases per 100,000 persons), while the rate among non-U.S.-born persons declined 1.5\% (to 14.1) (Table 2) (Figure).

Among non-U.S.-born persons residing in the United States, TB rates during 2019 were highest among Asians (25.7 per 100,000), followed by Native Hawaiians/Pacific Islanders (25.1), blacks/African Americans (19.5), Hispanics/Latinos (10.2), and American Indians/Alaska Natives (5.3) and were lowest among whites (3.1) (Table 2). Rates decreased from 2018 to 2019 for all non-U.S.-born groups except American Indians/Alaska Natives and Native Hawaiians/Pacific Islanders. The top five countries of birth among non-U.S.-born persons with incident TB in 2019 were Mexico (1,165 cases; $18.4 \%$ of non-U.S.-born cases), the Philippines (790; 12.5\%), India (573; 9.1\%), Vietnam (503; 8.0\%), and China (387; 6.1\%).

Among U.S.-born persons, 2019 rates were highest for Native Hawaiians/Pacific Islanders (3.5), followed by American Indians/Alaska Natives (3.4), blacks/African Americans (2.5), Hispanics/Latinos (1.6), and Asians (1.6) and were lowest

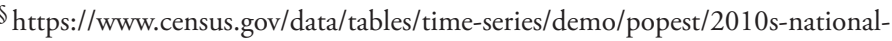
total.html.

Sttps://www.census.gov/programs-surveys/cps/data/data-tools.html.
} 
TABLE 1. Tuberculosis (TB) case counts and rates with annual percentage changes, by U.S. Census division and state or district United States, 2018 and 2019

\begin{tabular}{|c|c|c|c|c|c|c|}
\hline \multirow{2}{*}{$\begin{array}{l}\text { Census division/ } \\
\text { State }\end{array}$} & \multicolumn{3}{|c|}{ No. of reported TB cases* } & \multicolumn{3}{|c|}{ TB rate $^{\dagger}$} \\
\hline & 2018 & 2019 & $\%$ change & 2018 & 2019 & $\%$ change $^{\S}$ \\
\hline \multicolumn{7}{|c|}{ Division 1: New England } \\
\hline Connecticut & 51 & 67 & 31.4 & 1.4 & 1.9 & 31.6 \\
\hline Maine & 14 & 19 & 35.7 & 1.0 & 1.4 & 35.2 \\
\hline Massachusetts & 200 & 179 & -10.5 & 2.9 & 2.6 & -10.6 \\
\hline New Hampshire & 12 & 6 & -50.0 & 0.9 & 0.4 & -50.2 \\
\hline Rhode Island & 20 & 14 & -30.0 & 1.9 & 1.3 & -30.1 \\
\hline Vermont & 5 & 3 & -40.0 & 0.8 & 0.5 & -40.0 \\
\hline Subtotal & 302 & 288 & -4.6 & 2.0 & 1.9 & -4.7 \\
\hline \multicolumn{7}{|c|}{ Division 2: Middle Atlantic } \\
\hline New Jersey & 291 & 311 & 6.9 & 3.3 & 3.5 & 6.9 \\
\hline New York & 744 & 754 & 1.3 & 3.8 & 3.9 & 1.7 \\
\hline Pennsylvania & 213 & 198 & -7.0 & 1.7 & 1.5 & -7.1 \\
\hline Subtotal & 1,248 & 1,263 & 1.2 & 3.0 & 3.1 & 1.4 \\
\hline \multicolumn{7}{|c|}{ Division 3: East North Central } \\
\hline Illinois & 319 & 327 & 2.5 & 2.5 & 2.6 & 2.9 \\
\hline Indiana & 116 & 108 & -6.9 & 1.7 & 1.6 & -7.4 \\
\hline Michigan & 108 & 132 & 22.2 & 1.1 & 1.3 & 22.2 \\
\hline Ohio & 178 & 150 & -15.7 & 1.5 & 1.3 & -15.8 \\
\hline Wisconsin & 49 & 51 & 4.1 & 0.8 & 0.9 & 3.8 \\
\hline Subtotal & 770 & 768 & -0.3 & 1.6 & 1.6 & -0.3 \\
\hline \multicolumn{7}{|c|}{ Division 4: West North Central } \\
\hline lowa & 49 & 52 & 6.1 & 1.6 & 1.6 & 5.9 \\
\hline Kansas & 28 & 38 & 35.7 & 1.0 & 1.3 & 35.6 \\
\hline Minnesota & 172 & 147 & -14.5 & 3.1 & 2.6 & -15.0 \\
\hline Missouri & 80 & 70 & -12.5 & 1.3 & 1.1 & -12.7 \\
\hline Nebraska & 27 & 17 & -37.0 & 1.4 & 0.9 & -37.3 \\
\hline North Dakota & 13 & 18 & 38.5 & 1.7 & 2.4 & 37.7 \\
\hline South Dakota & 12 & 16 & 33.3 & 1.4 & 1.8 & 32.4 \\
\hline Subtotal & 381 & 358 & -6.0 & 1.8 & 1.7 & -6.4 \\
\hline \multicolumn{7}{|c|}{ Division 5: South Atlantic } \\
\hline Delaware & 22 & 19 & -13.6 & 2.3 & 2.0 & -14.4 \\
\hline $\begin{array}{l}\text { District of } \\
\text { Columbia }\end{array}$ & 36 & 24 & -33.3 & 5.1 & 3.4 & -33.7 \\
\hline Florida & 591 & 558 & -5.6 & 2.8 & 2.6 & -6.6 \\
\hline Georgia & 271 & 301 & 11.1 & 2.6 & 2.8 & 10.0 \\
\hline Maryland & 210 & 212 & 1.0 & 3.5 & 3.5 & 0.8 \\
\hline North Carolina & 196 & 185 & -5.6 & 1.9 & 1.8 & -6.6 \\
\hline South Carolina & 86 & 80 & -7.0 & 1.7 & 1.6 & -8.1 \\
\hline Virginia & 205 & 190 & -7.3 & 2.4 & 2.2 & -7.7 \\
\hline West Virginia & 6 & 10 & 66.7 & 0.3 & 0.6 & 67.8 \\
\hline Subtotal & 1,623 & 1,579 & -2.7 & 2.5 & 2.4 & -3.5 \\
\hline
\end{tabular}

among whites (0.4). TB incidence decreased from 2018 to 2019 for all U.S.-born groups except Hispanics.

Human immunodeficiency virus (HIV) status was known for $87.3 \%$ of reported $2019 \mathrm{~TB}$ cases; $4.9 \%$ of those patients were coinfected with HIV, including $7.8 \%$ of persons aged $25-44$ years. Initial drug-susceptibility testing results for at least isoniazid and rifampin were reported for $94.9 \%$ of culture-confirmed cases during 2018, the most recent year for which complete data are available.**Among

\footnotetext{
** Because initial drug-susceptibility test results for isoniazid and rifampin were only available for $86.4 \%$ of culture-confirmed cases during 2019, more complete data from 2018 are presented. Culture-confirmed cases are defined as cases that were culture-positive on a specimen collected $\leq 2$ weeks after starting TB treatment.
}

TABLE 1. (Continued) Tuberculosis (TB) case counts and rates with annual percentage changes, by U.S. Census division and state or district - United States, 2018 and 2019

\begin{tabular}{|c|c|c|c|c|c|c|}
\hline \multirow{2}{*}{$\begin{array}{l}\text { Census division/ } \\
\text { State }\end{array}$} & \multicolumn{3}{|c|}{ No. of reported TB cases* } & \multicolumn{3}{|c|}{$\mathrm{TB}$ rate ${ }^{\dagger}$} \\
\hline & 2018 & 2019 & $\%$ change & 2018 & 2019 & $\%$ change $^{\S}$ \\
\hline \multicolumn{7}{|c|}{ Division 6: East South Central } \\
\hline Alabama & 91 & 87 & -4.4 & 1.9 & 1.8 & -4.7 \\
\hline Kentucky & 65 & 66 & 1.5 & 1.5 & 1.5 & 1.4 \\
\hline Mississippi & 81 & 58 & -28.4 & 2.7 & 1.9 & -28.3 \\
\hline Tennessee & 139 & 128 & -7.9 & 2.1 & 1.9 & -8.7 \\
\hline Subtotal & 376 & 339 & -9.8 & 2.0 & 1.8 & -10.2 \\
\hline \multicolumn{7}{|c|}{ Division 7: West South Central } \\
\hline Arkansas & 76 & 63 & -17.1 & 2.5 & 2.1 & -17.3 \\
\hline Louisiana & 105 & 89 & -15.2 & 2.3 & 1.9 & -15.0 \\
\hline Oklahoma & 74 & 72 & -2.7 & 1.9 & 1.8 & -3.1 \\
\hline Texas & 1,124 & 1,153 & 2.6 & 3.9 & 4.0 & 1.3 \\
\hline Subtotal & 1,379 & 1,377 & -0.1 & 3.4 & 3.4 & -1.1 \\
\hline \multicolumn{7}{|c|}{ Division 8: Mountain } \\
\hline Arizona & 178 & 184 & 3.4 & 2.5 & 2.5 & 1.7 \\
\hline Colorado & 64 & 66 & 3.1 & 1.1 & 1.1 & 1.9 \\
\hline Idaho & 15 & 7 & -53.3 & 0.9 & 0.4 & -54.3 \\
\hline Montana & 5 & 2 & -60.0 & 0.5 & 0.2 & -60.3 \\
\hline Nevada & 69 & 52 & -24.6 & 2.3 & 1.7 & -25.9 \\
\hline New Mexico & 41 & 40 & -2.4 & 2.0 & 1.9 & -2.6 \\
\hline Utah & 18 & 27 & 50.0 & 0.6 & 0.8 & 47.5 \\
\hline Wyoming & 1 & 1 & 0.0 & 0.2 & 0.2 & -0.2 \\
\hline Subtotal & 391 & 379 & -3.1 & 1.6 & 1.5 & -4.4 \\
\hline \multicolumn{7}{|l|}{ Division 9: Pacific } \\
\hline Alaska & 63 & 59 & -6.3 & 8.6 & 8.1 & -5.9 \\
\hline California & 2,097 & 2,118 & 1.0 & 5.3 & 5.4 & 0.9 \\
\hline Hawaii & 120 & 99 & -17.5 & 8.4 & 7.0 & -17.2 \\
\hline Oregon & 81 & 70 & -13.6 & 1.9 & 1.7 & -14.3 \\
\hline Washington & 190 & 223 & 17.4 & 2.5 & 2.9 & 16.0 \\
\hline Subtotal & 2,551 & 2,569 & 0.7 & 4.8 & 4.8 & 0.4 \\
\hline Total & 9,021 & 8,920 & -1.1 & 2.8 & 2.7 & -1.6 \\
\hline
\end{tabular}

* Based on data from the National Tuberculosis Surveillance System as of March 3, 2020.

† Cases per 100,000 persons. Calculated using midyear population estimates from the U.S. Census Bureau.

$\S$ Calculated using unrounded figures.

the 6,746 cases during 2018 with available drug-susceptibility test data, $102(1.5 \%)$ were multidrug-resistant ${ }^{\dagger \dagger} ; 88(86.3 \%)$ of these cases were among non-U.S.-born persons; 83 (81.4\%) reported no previous TB episode. One case of extensively drugresistant $\mathrm{TB} \$ \$$ was reported during 2018; this case occurred in a non-U.S.-born person with a reported previous episode of TB disease.

\section{Discussion}

Since adoption of the U.S. TB elimination strategy in 1989 (1), TB incidence has decreased by approximately two thirds (2), demonstrating the effectiveness of efforts during the last three decades to prevent TB transmission in the United States.

\footnotetext{
$\dagger \dagger$ A case of TB caused by a strain of Mycobacterium tuberculosis that is resistant to at least isoniazid and rifampin.

$\$ \$$ A case of TB caused by a strain of Mycobacterium tuberculosis that is resistant to isoniazid, rifampin, any fluoroquinolone, and at least one injectable secondline drug (i.e., amikacin, kanamycin, or capreomycin).
} 
TABLE 2. Tuberculosis (TB) case counts and rates, by national origin and race/ethnicity — United States, 2016-2019

\begin{tabular}{|c|c|c|c|c|}
\hline \multirow{2}{*}{$\begin{array}{l}\text { U.S. population } \\
\text { group }\end{array}$} & \multicolumn{4}{|c|}{ No. of cases* (rate $\left.^{\dagger}\right)$} \\
\hline & 2016 & 2017 & 2018 & 2019 \\
\hline \multicolumn{5}{|l|}{ U.S.-born ${ }^{\S}$ persons } \\
\hline Hispanic/Latino & $593(1.6)$ & $582(1.5)$ & $589(1.5)$ & $628(1.6)$ \\
\hline White & $904(0.5)$ & $790(0.4)$ & $807(0.4)$ & $756(0.4)$ \\
\hline $\begin{array}{l}\text { Black/African } \\
\text { American }\end{array}$ & $1,057(3.0)$ & $999(2.8)$ & $950(2.7)$ & $905(2.5)$ \\
\hline Asian & $144(2.1)$ & $134(1.9)$ & 137 (1.9) & $120(1.6)$ \\
\hline $\begin{array}{l}\text { American Indian/ } \\
\text { Alaska Native }\end{array}$ & $110(5.1)$ & $91(3.8)$ & $102(4.0)$ & $79(3.4)$ \\
\hline $\begin{array}{l}\text { Native Hawaiian/ } \\
\text { Pacific Islander }\end{array}$ & $30(4.1)$ & $45(6.5)$ & $42(5.6)$ & $23(3.5)$ \\
\hline $\begin{array}{l}\text { Multiple or } \\
\text { unknown race/ } \\
\text { ethnicity }\end{array}$ & 22 (一ף) & 28 (-9) & $31(-9)$ & $42($ - $)$ \\
\hline Subtotal & $2,860(1.0)$ & $2,669(1.0)$ & $2,658(1.0)$ & $2,553(0.9)$ \\
\hline \multicolumn{5}{|c|}{ Non-U.S.-born persons } \\
\hline Hispanic/Latino & $1,976(10.0)$ & $1,959(9.9)$ & $2,039(10.3)$ & $2,065(10.2)$ \\
\hline White & $281(3.7)$ & $266(3.4)$ & $261(3.2)$ & $250(3.1)$ \\
\hline $\begin{array}{l}\text { Black/African } \\
\text { American }\end{array}$ & $911(22.7)$ & $899(22.2)$ & $846(20.3)$ & 825 (19.5) \\
\hline Asian & $3,055(27.2)$ & $3,128(27.3)$ & $3,069(26.0)$ & $3,000(25.7)$ \\
\hline $\begin{array}{l}\text { American Indian/ } \\
\text { Alaska Native }\end{array}$ & $1(2.9)$ & $2(2.9)$ & $2(3.5)$ & $3(5.3)$ \\
\hline $\begin{array}{l}\text { Native Hawaiian/ } \\
\text { Pacific Islander }\end{array}$ & $46(12.7)$ & $67(22.7)$ & $72(24.4)$ & $81(25.1)$ \\
\hline $\begin{array}{l}\text { Multiple or } \\
\text { unknown race/ } \\
\text { ethnicity }\end{array}$ & 64 (一ף) & $52(-9)$ & $70($ - & $98($ (-) \\
\hline Subtotal & $6,334(14.7)$ & 6,373 (14.7) & $6,359(14.3)$ & $6,322(14.1)$ \\
\hline $\begin{array}{l}\text { Unknown national } \\
\text { origin }\end{array}$ & $5(-9)$ & $7(-9)$ & $4(-\pi)$ & $45(-9)$ \\
\hline Total & $9,199(2.8)$ & $9,049(2.8)$ & $9,021(2.8)$ & $8,920(2.7)$ \\
\hline
\end{tabular}

* Based on data from the National Tuberculosis Surveillance System as of March 3, 2020.

† Cases per 100,000 persons. Rates according to national origin and race/ ethnicity were calculated using midyear population estimates from the Current Population Survey. Total rate was calculated using midyear population estimates from the U.S. Census Bureau.

$\S$ U.S.-born persons were those born in the United States or U.S. territories (American Samoa, Northern Mariana Islands, Guam, Puerto Rico, or U.S. Virgin Islands) or born elsewhere to a U.S. citizen. Non-U.S.-born persons were born outside the United States and U.S. territories, and include those born in the sovereign freely associated states (Federated States of Micronesia, Marshall Islands, or Palau) unless one or both parents were U.S. citizens.

"Rates could not be calculated for these categories because population estimates are not available.

However, the pace of progress has slowed since 2012 (3). This slowing is primarily related to the declining proportion of $\mathrm{TB}$ cases caused by recent transmission within the United States, against which the U.S. TB elimination strategy has been most effective (4). Currently, approximately $80 \%$ of TB cases result from reactivation of LTBI acquired years in the past, often outside the United States (2).

This shift in U.S. TB epidemiology from being driven primarily by recent transmission within the United States to reactivation of LTBI acquired in the past (often outside the United States) requires an expanded strategy that increases

\section{Summary}

What is already known about this topic?

Tuberculosis (TB) incidence in the United States has steadily declined since 1993, but the pace of decline has slowed in recent years.

What is added by this report?

The U.S. TB rate during 2019 declined to 2.7 cases per 100,000 persons, the lowest level on record. However, the annual pace of decline (-1.6\% from 2018) remains slow, particularly among TB cases that are attributed to reactivation of latent TB infection (LTBI).

What are the implications for public health practice?

To eliminate TB, the United States needs to expand testing and treatment for LTBI while continuing to prevent TB transmission. Partnerships with health care providers, including private providers, are essential for this strategy's success.

emphasis on detecting and treating LTBI. However, this expanded focus on LTBI cannot compromise existing efforts to prevent TB transmission if the United States is to avoid another TB resurgence, as occurred in the late 1980s and early 1990s (5). The U.S. Preventive Services Task Force and CDC recommend routine LTBI screening for populations at increased risk, including persons who have lived in countries with increased TB prevalence and persons who have resided in high-risk congregate settings (e.g., homeless shelters or correctional facilities) (6). The efficacy and cost-effectiveness of LTBI screening and treatment, when implemented in populations at risk, compare favorably with other widely accepted preventive care interventions, including mammography to screen for breast cancer ( 7 ) and use of statins to prevent cardiovascular disease (8). LTBI screening (and treatment as indicated) should therefore be considered a routine and integral part of primary care for patients at elevated risk for LTBI.

The findings in this report are subject to at least four limitations. First, this analysis is based on provisional case counts for 2019; however, in previous years, final case counts and rates have not differed greatly from the provisional figures. Second, rates were calculated using estimated population denominators; as a result, rates might change slightly as population estimates are refined in the future. Third, incidence trends for some demographic groups with few patients, e.g., non-U.S.-born American Indian/Alaska Natives, should be interpreted cautiously because of the increased volatility in these rates. Finally, complete drug susceptibility test data are not available for 2019 because susceptibility testing might take several weeks to complete because of the slow-growing nature of Mycobacterium tuberculosis.

Concerns regarding the potential adverse effects of LTBI treatment have been an important barrier to LTBI screening and treatment in the past (9). To address these concerns, 
FIGURE. Tuberculosis (TB) case counts and rates, by national origin*,† — United States, 2007-2019

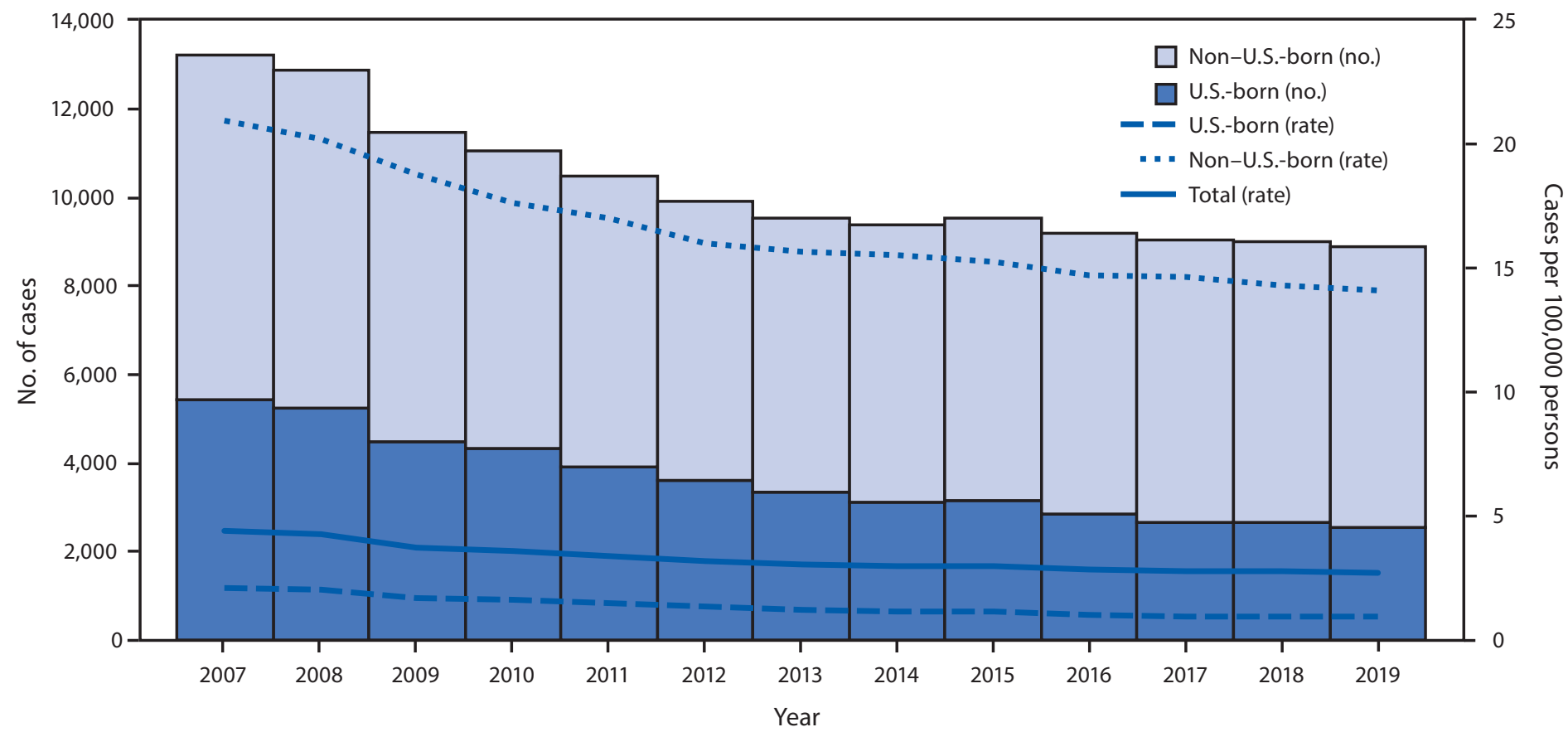

* Number of cases with unknown national origin not shown (range $=2-60$ per year; median $=7$ ). Total rate includes cases with unknown national origin.

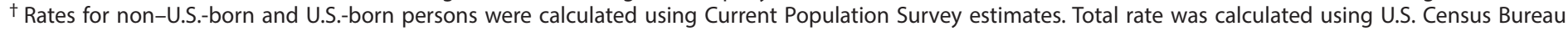
population estimates.

CDC and the National Tuberculosis Controllers Association have released new guidelines that recommend short-course, rifamycin-based regimens, which have less toxicity and better completion rates than does isoniazid monotherapy (10). CDC will continue to support and encourage public health partners and primary care providers to increase adoption of LTBI testing and treatment guidelines to accelerate progress toward TB elimination.

\section{Acknowledgments}

State, local, and territorial health department personnel; Cynthia Adams, Stacey Parker, Jeanette Roberts, Katrina Williams, Chief Information Officer Solutions and Partners (CIO-SP3) DTBE Task Order; Maryam Haddad, Benjamin Silk, Amish Talwar, Clarisse Tsang, Billy Walker, Jonathan Wortham, National Center for HIV/ AIDS, Viral Hepatitis, STD, and TB Prevention, CDC.

Corresponding author: Noah G. Schwartz,nschwartz@cdc.gov, 404-718-3584.

${ }^{1}$ Division of Tuberculosis Elimination, National Center for HIV/AIDS, Viral Hepatitis, STD, and TB Prevention, CDC; ${ }^{2}$ Epidemic Intelligence Service, CDC.

All authors have completed and submitted the International Committee of Medical Journal Editors form for disclosure of potential conflicts of interest. No potential conflicts of interest were disclosed.

\section{References}

1. Dowdle WR. A strategic plan for the elimination of tuberculosis in the United States. MMWR Suppl 1989;38(No. SS-3).
2. CDC. Reported tuberculosis in the United States, 2018. Atlanta, GA: US Department of Health and Human Services, CDC; 2019. https:// www.cdc.gov/tb/statistics/reports/2018/default.htm

3. Armstrong LR, Winston CA, Stewart B, Tsang CA, Langer AJ, Navin TR. Changes in tuberculosis epidemiology, United States, 1993-2017. Int J Tuberc Lung Dis 2019;23:797-804. https://doi.org/10.5588/ ijtld.18.0757

4. Menzies NA, Cohen T, Hill AN, et al. Prospects for tuberculosis elimination in the United States: results of a transmission dynamic model. Am J Epidemiol 2018;187:2011-20. https://doi.org/10.1093/aje/kwy094

5. Cantwell MF, Snider DE Jr, Cauthen GM, Onorato IM. Epidemiology of tuberculosis in the United States, 1985 through 1992. JAMA 1994;272:535-9. https://doi.org/10.1001/jama.1994.03520070055038

6. CDC. Latent TB infection testing and treatment: summary of U.S. recommendations [Factsheet]. Atlanta, GA: US Department of Health and Human Services, CDC; 2019. https://www.cdc.gov/tb/publications/ltbi/ pdf/CDC-USPSTF-LTBI-Testing-Treatment-Recommendations-508.pdf

7. Linas BP, Wong AY, Freedberg KA, Horsburgh CR Jr. Priorities for screening and treatment of latent tuberculosis infection in the United States. Am J Respir Crit Care Med 2011;184:590-601. https://doi. org/10.1164/rccm.201101-0181OC

8. Chou R, Dana T, Blazina I, Daeges M, Jeanne TL. Statins for prevention of cardiovascular disease in adults: evidence report and systematic review for the US Preventive Services Task Force. JAMA 2016;316:2008-24. https://doi.org/10.1001/jama.2015.15629

9. Alsdurf H, Hill PC, Matteelli A, Getahun H, Menzies D. The cascade of care in diagnosis and treatment of latent tuberculosis infection: a systematic review and meta-analysis. Lancet Infect Dis 2016;16:1269-78. https://doi.org/10.1016/S1473-3099(16)30216-X

10. Sterling TR, Njie G, Zenner D, et al. Guidelines for the treatment of latent tuberculosis infection: recommendations from the National Tuberculosis Controllers Association and CDC, 2020. MMWR Recomm Rep 2020;69(No. RR-1). https://doi.org/10.15585/mmwr.rr6901a1 